been in operation about twelve years, and has have been collected by a large number of obserproved itself capable of exact and valuable work; vers, all of them medical officers of education and no instance of willful dereliction of duty under intelligence, yet each differing from the other in it has taken place. It has now the commenda- powers of observation, and in mental charactertion of judges, prosecuting officers, and the gen- istics or peculiarities.

eral public, and may fairly be pronounced a step in the direction of purifying the public service."

The limit of time at my disposal prevents a more detailed discussion of a subject of such vast importance, and in closing I desire to commend for earnest consideration in each of the several States the following propositions :

I. To abolish the office of coroner.

2. To dispense with jury service.

3. To separate the medical from the legal duties in all cases involving the examination into the causes of death where crime is suspected.

4. To entrust the medical examination only to competent medical officers properly trained in their work.

5. To make the number of these medical officers as small as consistent with the proper discharge of their dutiès.

6. To consign all questions of law only to properly qualified legal magistrates.

7. To remove the appointment of these officers entirely from the question of political consideration; and to be based only upon their possession of the requisite and proper qualifications.

Upon some basis of this character should the coroner's laws be revised. Much useless expenditure of time and money will be avoided, often great sorrow and anxiety will be prevented, and that which is of vastly greater importance, the ends of justice will be far better served.

\section{SICKNESS AND MORTALITY IN THE} ARMY OF THE UNITED STATES. Read in the Section of State Medicine, at the Forty-second Annual
Meeting of the American Medical Association, held at Washing. ton, D. C., May, I\&gr

BY JOS. R. SMITH, A.M., M.D.,

COLONEL AND SURGEON, U, S. ARMY; MEDICAL DIRECTOR DEPART-

All statistics telling the amount of disease and death in any considerable portion of the community, and showing the variations in said amount from year to year, seem properly to belong to State Medicine.

As there is no Section of military medicine and surgery in the American Medical Association, I deem it proper to present to the Section on State Medicine the following paper, in which I bave collated and compared figures showing the absolute and relative amount of disease, death, and non-effectiveness in the Army of the United States.

While these statistics bave been collected under conditions of considerable uniformity from year to year, yet it is to be remarked, that they
To some, this last named fact will make the statistics more reliable and valuable, than if they had been collated and reported by a single individual; to others, less reliable and valuable.

In 1882, I presented to the American Medical Association a paper which was printed in its Transactions, and contained the health statistics of the U. S. Army for eleven years-from I87I to $\mathrm{I} 88 \mathrm{I}$ inclusive.

I now present similar data from the annual reports of the Surgeon-General for a period of nine years, from 1882 to 1889 inclusive.

\section{TABI,E I,}

Showing the Sickness and Mortality from Disease in the Army of the United States during the years I882-1889, inclusive.

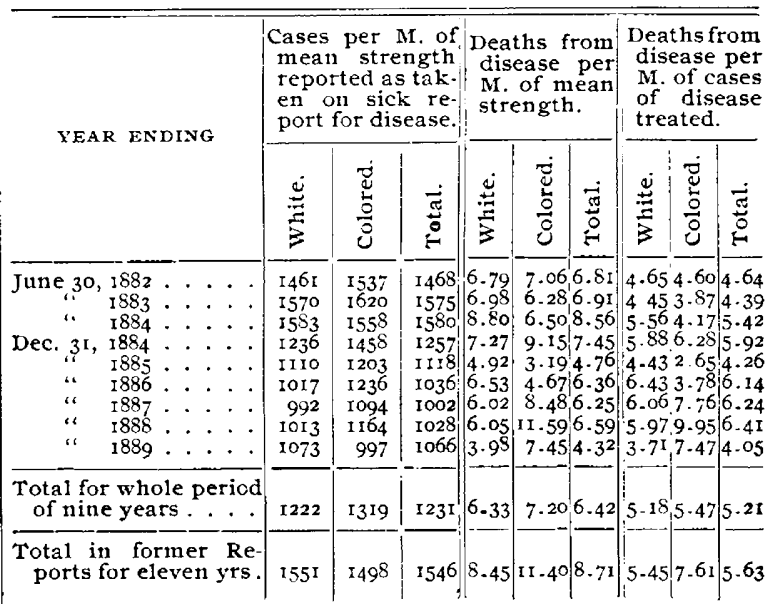

The number taken sick or dying from disease, and the number constantly sick at different times, are both, in their own way, measures of the health of an army; each has its own peculiar value.

The difference between the numbers admitted on sick report for disease in the two periods tabulated in 1882 and now, might be due to difference of physique of the soldiers, to differences in the nature of their service, and to differences in the sanitary care and attention bestowed upon them.

So far as can be discovered, the material in both periods was about the same; the nature of the service was unchanged. So, reasoning by exclusion, better sanitary care and attention must have been mainly or entirely operative in causing the decrease of numbers taken sick during the period 1882 to 1889 inclusive.

Differences in the ratios of those dying from disease (not injury) per $I, 000$ of mean strength, might be due to these above named causes, and, in addition, to a difference in the character or constitution of each individual disease, and to better therapeusis. 
As before, the first two causes may be excluded. A difference in the character of the diseases has not been proved, or even asserted; rest, the improvements in sanitation and therapeusis, as the effective factors.

The difference in the ratio of those dying from disease per 1,000 of cases of disease, would seem, besides the above named causes, specially due to either a difference in the character of the disease; that is, a greater or less tendency to death, or to better treatment, these two being either combined or complementary; one more efficient as the other is less so.

The importance of the ratios of constant noneffectiveness as a measure of comparative health, was first emphasized by the Surgeon-General of the Army in his report for I 888 . The writer of the pages in that report, on the health of the Army as a whole, says: "The actual impairment of force which the Army suffers on account of sickness, as well as the relative importance of the various causes of sickness, cannot be measured with any degree of accuracy by the number of admissions to sick report, but they are shown very clearly by the aggregate loss of time which these admissions individually and collectively cause, and from this aggregate the average noneffectiveness can be accurately and readily determined."
So it is desirable to consider these data, and I have accordingly constructed a new table, containing figures relating to non-effectiveness. I have also added the ratios of "deaths from all causes," the foregoing tables including only those from disease. It is apparent that the difference between the ratios of deaths from disease, and deaths from all causes, is the ratio of deaths from injury, violence, etc.

I have deemed it best also to add the figures for some years preceding i $87 \mathrm{I}$-and I have commenced with I 867 , because during that year the Army was reduced from a war to a peace footing, and because in that year appeared first the statistics of average or mean strength (termed in the reports "average" for the years I 867 , I 868, I 869 , I 886 , I 887 , I 888 and $\mathrm{I} 889$, and "average mean" for other years), the number taken on sick report for disease, the number taken on sick report for injury, the mortality, and the constant sickness rate, all for whites and blacks separately, for the fiscal year ending June 30 , to which year the rest of the report refers. Similar data have appeared in each annual report since, until I 885 .

In the annual report dated October I, I 885, and subsequent annual reports of the SurgeonGeneral, while the rest of the report refers to the previous fiscal year, ending June 30 , the health statistics relate to the calendar year next preceding. TABLE II.

\begin{tabular}{|c|c|c|c|c|c|c|c|c|c|c|c|c|c|c|c|c|c|c|}
\hline \multirow{2}{*}{ YEAR ENDING } & \multicolumn{3}{|c|}{$\begin{array}{l}\text { Ratio, per M. of } \\
\text { mean strength, } \\
\text { admitted for dis- } \\
\text { ease. }\end{array}$} & \multicolumn{3}{|c|}{$\begin{array}{l}\text { Ratio of deaths } \\
\text { from disease, per } \\
\text { M. of mea n } \\
\text { strength. }\end{array}$} & \multicolumn{3}{|c|}{$\mid \begin{array}{l}\text { Ratio of deaths } \\
\text { from disease, per } \\
\text { M. admitted for } \\
\text { disease. }\end{array}$} & \multicolumn{3}{|c|}{$\begin{array}{l}\text { Ratio of deaths } \\
\text { from all causes, } \\
\text { per M. of mean } \\
\text { strength. }\end{array}$} & \multicolumn{3}{|c|}{$\begin{array}{l}\text { Ratio of deaths } \\
\text { from all causes, } \\
\text { per } \mathbf{M} \text {. of admis- } \\
\text { sions for all } \\
\text { causes. }\end{array}$} & \multicolumn{3}{|c|}{$\begin{array}{l}\text { Ratio constantly } \\
\text { sick, per M. of } \\
\text { mean strength. }\end{array}$} \\
\hline & 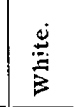 & 离 & : & $\stackrel{5}{3}$ & 芯 & $\begin{array}{l}\overrightarrow{5} \\
\stackrel{5}{0} \\
\vec{H}\end{array}$ & $\stackrel{\stackrel{ \pm}{2}}{3}$ & 苟 & 矛 & 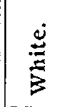 & $\frac{3}{0}$ & ڤ్ & 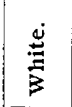 & 营 & 吾 & 莣 & 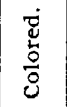 & \\
\hline & 2717 & & & & & & I & & 17.46 & & & & & & & 58.00 & & \\
\hline & & & & & & & & & & & & & & & & & & \\
\hline 1 & & & & & & & & 6 & 4 & & & & & & & & & \\
\hline 1 & & & & & & & & 9 & & & & & & & & & & \\
\hline 1 & & & & & & & & & & & & & & & & & & \\
\hline I & & & & & & & & & & & & & & & & & & \\
\hline ‘ & & & & & & & & & & & & & & & & & & \\
\hline I & & & & & & & & & & & & & & & & & & \\
\hline ' & & & & & & & 5. & & & & & & & & & & & \\
\hline 4 & & & & & & & & & & & & & & & & & & \\
\hline ' & & & & & & & & & & & & & & & & & & \\
\hline " & & & & & & & & 6. & & & & & & & & & & \\
\hline " & & & & 7. & & & & & & & & & & & & & & \\
\hline '" & & & & & & & & 5. & & & & & & & & & & \\
\hline " & & & & & II & 6. & & & & & & & & & & & & \\
\hline " & & & & & & & & & & 10 & & & & & & & & \\
\hline " 18 & & & & & & & & & & & & & & & & & & \\
\hline " 1884 & & & & 8.8 & & & & & & & & & & & & & & \\
\hline 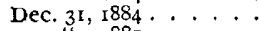 & 12 & & & 7. & & 7 . & 5. & 6. & & & & & & & & & 48 & $\begin{array}{l}44.48 \\
44.48\end{array}$ \\
\hline 1 & & & & & & & 4. & & & 7.66 & & & & & & & & \\
\hline t" & I0 & & & 6. & & 6 & & & & 9.94 & & & & & & & & \\
\hline 14 & & & & & & & & & & & & & & & & & & \\
\hline " & 1013 & II & & 6.0 & II.59 & 6. & 5. & & 6.4 & 8.16 & & & 6.5 & & & 41.6 & & \\
\hline $100 y$ & 1073 & 997 & 1066 & 3.98 & 7.45 & $4 \cdot 3^{2}$ & $3.7 \mathrm{I}$ & 7.47 & 4.05 & 6.55 & 10.34 & 6.92 & 4.97 & 8.07 & 5.26 & 44.44 & 41.09 & 44.12 \\
\hline
\end{tabular}

TABLE III

\begin{tabular}{|c|c|c|c|c|c|c|c|c|c|c|c|c|c|c|c|c|c|c|}
\hline $\begin{array}{l}\text { For the four years, } 1867 \\
\text { to } 1870 \text {, inclusive }\end{array}$ & 2420 & 2407 & 2427 & 21.78 & 57.77 & 26.78 & 8.96 & 24.00 & 10.62 & $25 \cdot 5^{\mathrm{I}}$ & 63.19 & 29.69 & 9.43 & 24.31 & 11,02 & 57.80 & 50.93 & 57.04 \\
\hline $\begin{array}{l}\text { For eleven years, is } 1 \\
\text { to i } 88 \mathrm{r} \text {, inclusive. . . } \\
\text { For nine years, I } 882 \text { to }\end{array}$ & $155 \mathrm{I}$ & I 498 & I 546 & 8.45 & 11.40 & 8.71 & 5.45 & $7.6 \mathrm{r}$ & 5.63 & 14.01 & 17.68 & $14 \cdot 34$ & 7.72 & 10.15 & 7.93 & 45.85 & 45.01 & $45 \cdot 77$ \\
\hline $\begin{array}{l}\text { IS89, inclusive } \\
\text { For whole period of }\end{array}$ & I 222 & 1319 & I23I & 6.33 & 7.20 & 6.42 & 5.18 & 5.47 & 5.21 & $9 \cdot 36$ & I0.69) & 9.49 & 6.40 & $6.6 \mathrm{I}$ & 6.43 & 43.76 & 43.84 & 43.77 \\
\hline twenty-four years. & 1667 & 1708 & 1671 & II.14 & 23.69 & 12.35 & 6.68 & 13.87 & $7 \cdot 39$ & 15.42 & 28.82 & 16.72 & 8.02 & $14 \cdot 74$ & 8.67 & 44.10 & 42.45 & 43.93 \\
\hline
\end{tabular}


This and subsequent reports also fail to give the constant sickness rates for disease and injury separately. No reason was given for these changes, nor is one apparent which is entirely satisfactory.

In consequence of them, accurate, rigorous comparison is prevented between figures of preceding and subsequent reports, and the report referred to embraces statistics for six months common to it and the previous report.

Consequent on these omissions, my table does not contain the non-effective rates for disease and injury separately, but the rate for both combined.

This same report of the Surgeon-General, for the first time gives data as to the number of days' service lost in consequence of admissions to sick report.

Explanatory of some of the figures in these tables, the text of the reports of the SurgeonGeneral states that I, 3 Io deaths from cholera occurred in 1867 .

That cholera and yellow fever combined caused 68 I deaths in 1868 , and that yellow fever to a limited extent occurred in $1869,1874,1875,1876$, I $877,1878,1883$ and 1884 .

The text states that for the year 1870 , "the comparatively large mortality from wounds, accidents and injuries, is explained by the Indian hostilities;" and it shows the same, in 1876 , to be mainly due to the Custer massacre.

For the year ending June 30 , I884, the text reads: "It is interesting to note that not only is this the lowest death rate yet reached among colored troops since their organization, but it is the first time that the rate has fallen lower than that for white troops, the usual average difference being 3.2 per thousand of mean strength in favor of the latter class."

For the year 1885 , the text says: "It is a matter of congratulation that not only the admission rate for the troops, but also the deathrate, has fallen to a lower point than at any time within the history of the Medical Department."

I remark here that my tables show that, for the succeeding years I 886, I 887, I 888 and I 889 , the admission rates, though not the death-rates, for all causes, were still lower.

In the report for the year ending December $3 \mathrm{I}$, I 884 , the text of the report of the Surgeon-General mentions the "mean strength" obtained from the reports of the Adjutant General of the Army, which varies from the "mean strength" obtained from the reports of medical officers from which all preceding rates had been calculated. The text says that the death and discharge rates in these tables, so calculated, are "higher than they should be," as the figures given by medical officers do not embrace the whole strength of the Army. The subject was only considered of enough importance to be mentioned in a footnote merely, and it is so mentioned in a foot-note in the report of the ensuing year.
In the report for 1886 , the matter is more fully treated of, and the difference between the two " mean strengths" is fuliy recognized, that given by medical officers being generally the smaller.

The reason is shown why the "mean strength" reported by the Adjutant General is the proper strength from which to calculate ratios of deaths and discharges, and these ratios are, in the 1886 and subsequent reports, calculated from the figures of the Adjutant General, while rates of admission and non-effectiveness are calculated from the figures of mean strength given by medical officers-the same is the case for succeeding years. It may here be remarked that, from many points of view, this report of 1886 shows a distinct advance beyond its predecessors.

It is manifest that for purposes of comparison within themselves, the ratios of all reports must be calculated on similar data, and those data given.

As the data given in the reports before 1886 will not enable us to calculate ratios for these years on the figures of the Adjutant General, I have used for the ratios of every year in tables II and III, the figures given by medical officers.

The exact difference between these two "mean strengths" appears below, the figures being taken from all the annual reports of the Surgeon-General which give such figures. MEAN STRENGTH OF ARMY.

\begin{tabular}{|c|c|c|c|c|c|c|c|}
\hline \multirow{2}{*}{\multicolumn{2}{|c|}{ Y'EAR. }} & \multicolumn{2}{|c|}{ White. } & \multicolumn{2}{|c|}{ Colo:ed. } & \multicolumn{2}{|c|}{ Total. } \\
\hline & & 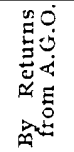 & 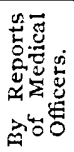 & 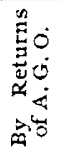 & 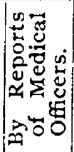 & 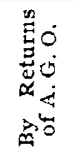 & 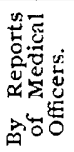 \\
\hline $\begin{array}{l}1884 . \\
1885 . \\
1886 . \\
1887 . \\
1888 . \\
1889 .\end{array}$ & 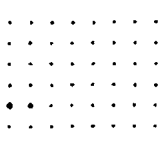 & $\begin{array}{l}\ldots \\
23,737 \\
23,937 \\
24,103 \\
24,723\end{array}$ & $\begin{array}{l}21,430 \\
21,601 \\
22,310 \\
22,591\end{array}$ & $\begin{array}{l}\cdot \dot{0} \\
2,358 \\
2,428 \\
2,636 \\
2,610\end{array}$ & $\mid$\begin{tabular}{l|}
$\cdots$ \\
2,142 \\
2,240 \\
2,416 \\
2,417
\end{tabular} & $\begin{array}{l}26,124 \\
26,542 \\
26,095 \\
26,365 \\
26,739 \\
27,333\end{array}$ & $\begin{array}{l}24,033 \\
24,138 \\
23,572 \\
23.841 \\
24,726 \\
25,008\end{array}$ \\
\hline
\end{tabular}

The difference in the ratios computed from these main strengths is given below :

\begin{tabular}{|c|c|c|c|c|c|c|c|c|}
\hline YEAR. & 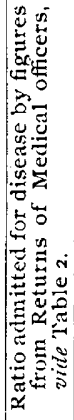 & 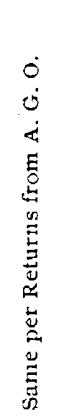 & 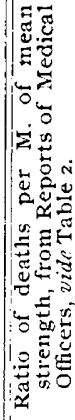 & 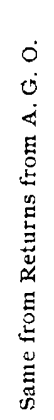 & 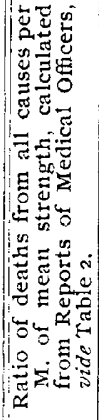 & 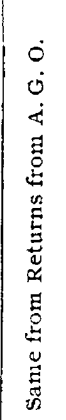 & 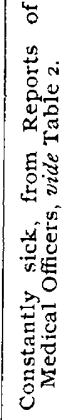 & 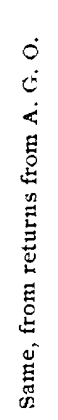 \\
\hline 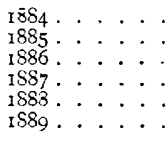 & $\begin{array}{l}1257 \\
1118 \\
1036 \\
1002 \\
1028 \\
1066\end{array}$ & $\begin{array}{r}\text { I157 } \\
\text { I0I } 7 \\
936 \\
906 \\
950 \\
976\end{array}$ & $\begin{array}{l}7.45 \\
4.76 \\
6.36 \\
6.25 \\
6.59 \\
4.32\end{array}$ & $\begin{array}{l}4.03 \\
5.75 \\
5.65 \\
6.09 \\
3.95\end{array}$ & $\begin{array}{r}10.94 \\
7.54 \\
9.76 \\
8.98 \\
8.82 \\
6.92\end{array}$ & $\begin{array}{r}10.02 \\
6.86 \\
8.81 \\
8.12 \\
8.15 \\
6.33\end{array}$ & $\begin{array}{l}44.48 \\
41.06 \\
39.41 \\
42.36 \\
41.90 \\
44.11\end{array}$ & $\begin{array}{l}40.92 \\
37.34 \\
35.60 \\
38.31 \\
38.74 \\
40.34\end{array}$ \\
\hline
\end{tabular}


Since 1883 , I have given much attention to the question of the correct mean strength of the Army. For many military posts, month after month, I have compared the figures in the reports of the Adjutant General, the figures given by medical officers, and the actual numbers on which these igures are based. It would take too much space to give all the grounds for my convictions, which I therefore merely recite, as follows:

As stated in the text of the report of the Surgeon-General for 1886 , the figures in the report of the Adjutant General are the proper data on which to compute ratios of deaths and discharges.

But neither the mean strength given by the Adjutant General, nor that obtained from reports of medical officers, are correct for the calculation of ratios of admission and constant sickness.

The figures of the Post-Surgeon should be the basis with certain additions which have been habitually omitted, but which may be easily ascertained and which may in future be supplied.

In consequence of using the figures given by Post-Surgeons, without the corrections above indicated. for comparison with the statistics of other armies, all the ratios in Tables 2 and 3 are too bigh; and the amount of correction should be probably in accordance with the figures immediately preceding, which show the differences as computed by the different mean strengths.

In the report of the Surgeon. General for the year ending June 30,1884 , the number of cases of typhoid fever is given in the different arms of the service, and among recruits and older soldiers. No attempt is made to explain the differing conditions of these different arms; and as it will hardly be supposed that typhoid fever favors a man simply because be is a cavalry or artillery man, the remarks under this head are not of very great significance.

Elsewhere remarks are made as to the greater or less prevalence of this disease at various posts, where more or less unsanitary condition is also treated of.

The next annual report, I885, again mentions the greater prevalence of the disease among cavalry men, and gives further details about the posts where prevalent.

Data are also given as to age and length of service of those affected.

In the same report appear tables to show the influence on mortality of rank, age, arm of service, race and nationality, and season of the year; also the relation of discharges for disability to arm of service, age, and season.

Data of a similar nature, more or less complete, appear in all subsequent reports.

The text of the report for I889 speaks of the death rate as the lowest annual death rate in the history of the Army, and makes pertinent com- ment on the effect produced by the number of discharges for disability on certain other health statistics of the Army.

On critical examination of the figures in Tables 2 and 3 , it will be evident, that taking for a measure the admission ratios on account of diseases exclusive of injury, the figures are most favorable for the black troops for the period of four years, $1868-70$ inclusive, and the period of eleven years I87I-8I inclusive; but most favorable for the white troops for the period of nine years I 882-9 inclusive, and the period of the whole twenty-four years.

Taking for our measure the mortality ratios the figures are most favorable for the white troops for each and every period given separately in Table 3 .

Taking for our measure the non-effective rate the figures are slightly in favor of the whites for nine years, I882-9 inclusive, and much more in favor of the blacks for all the other periods.

It farther appears that the death rates are more nearly equal for whites and blacks in the latter period of 9 years, $1882-9$ inclusive, than in the preceding two periods. That is to say, the blacks are overtaking the whites in the race of which longevity is the goal.

As regards the admission ratios for disease and the ratios for non effectiveness, the white troops in the last period of nine years have overtaken and a little passed the blacks.

For obvious reasons, the general deductions from the figures relating to longer periods of service are more valuable than those from the figures relating to individual years; yet attention may be called to the fact that for the last year, I 889 , the admission rate for disease and that for constant sickness are in favor of the black troops; while the mortality rates are considerably in favor of the white troops, while in general, the year, as regards vital statistics, was one of the best in the Army's history.

It will be further noticed that the indications from admission rate for disease, mortality rate, and constant sickness rate, are unanimously in favor of any one color but for seven years of the 24, viz: in 1874,1878, I $88 \mathrm{I}$, I 885, I 887 , and 1888 , in favor of the white; in 1884 in favor of the black troops.

For about three-quarters of the years given, the health of the white troops has been the best, as measured by rate of admission for disease and death rate.

Measured by rate of non-effectiveness, the white troops have been less affected by disease than the blacks for twelve years, and the blacks less than the whites for twelve years.

The maximum admission rate for disease among the whites, viz.: 27.17 per thousand of mean strength, occurred in 1867 ; the minimum, 992 , in 1887 . 
The maximum of the same rate among the colored troops, 28.65 per thousand, occurred in 1868; the minimum, 997 , in I 889 .

The maximum death rate per thousand of mean strength among the white troops, viz,: 37.15 occurred in 1867 ; the minimum 3.98 , in 1887 .

The maximum for the same rate among the colored troops, viz.: I 14.46 per thousand, occured in 1867 ; the minimum, 3.19 , in 1885 .

The maximum of non-effectiveness among the white troops, viz.: 63.02 per thousand, occurred in I 868 ; the minimum, 39.01 per thousand, in I 886 .

The maximum of the same among colored troops, 59.28 per thousand, occurred in 1868 ; the minimum, $37 \cdot 58$, in 1880 .

The maximum death rate for disease per thousand of cases of disease treated among the whites, viz.: 13.68 per thousand occurred in 1867 ; the minimum, $3.7 \mathrm{r}$, in 1889 .

The maximum of same ratio among colored troops, viz.: 39.95 per thousand occurred in 1867 ; the minimum 2.65 , in 1885 .

I am unable in the reports of the Surgeon-General or elsewhere to find facts reported which adequately explain all the fluctuations in the figures of Tables 2 and 3 , and without further remark I offer the foregoing figures and comments to the students of Army and other vital statistics, only adding that the figures given point unmistakably to the conclusion, that in the latter series of years tabulated, the amount of sickness and mortality was less than in the former series.

THE DUTY OF THE GOVERNMENT IN THE PREVENTION OF TUBERCU. LOSIS.

Read in the Section of State Medicine, at the Forly-second Annual Meeting of the American Medical Association, held at Washington, D. C., May 5, 1891 .

BY LAWRENCE F. FLICK, M.D., OF PHILADELPHIA, PA.

We read in the Declaration of Independence of the United States, "We hold these truths to be self.evident, that all men are created equal; that they are endowed by their Creator with certain unalienable rights; that among these are life, liberty, and the pursuit of happiness. That, to secure these rights, governments are instituted among men" .... All governments, indeed, which have been constituted upon the principles laid down in the great Magna Charta, have, as one of their foremost duties, the preservation of the lives and health of the people. The Common Law of England sums up the rights of individuals under three principal articles; namely : " the right of personal security, the right of personal liberty, and the right of private property ;" and defines the right of per- sonal security to consist, "in a person's legal right and uninterrupted enjoyment of his life, his limbs, his health, and his reputation."

In the earlier days of civilization many diseases were looked upon as providential visitations, and therefore non-preventable. In the Common Law of England, however, the principle that the government is bound to take every possible precaution against the spread of disease is well defined, not only indirectly by declaring for the preservation of life and bealth, but directly by providing penalties for persons offending against public health, or spreading such diseases as were then looked upon as contagious. The Common Law of England is operative in principle in most of the States of our Union; and its provision for life and health are affirmed in the Constitution of probably most of the States. Section I of the Constitution of Pennsylvania reads: "All men are born equally free and independent, and have certain inherent and indefeasable rights, among which are those of enjoying and defending life and liberty, etc." The words defending life must be given a broader interpretation than mere defense against the anger of a fellow man. A reasonable interpretation makes it a defense against every danger to life for which the ingenuity of man has constructed a defense.

Modern science teaches us that many of the diseases, which were formerly looked upon as divine visitations, are but ordinary warfares between various forms of organic life for selfexistence; and that when death ensues it is the going under of the weakest and the survival of the fittest. Man, the most perfect and the most intelligent of all of God's creatures, falls a victim to the onslaughts of organisms so minute that they can only be seen by the aid of most powerful lenses. What these little warriors lack in size they make up in number, and in their great power of reproduction and multiplication. The organism of man, so perfect in its construction, so complex in its machinery, and so complete in its equipment for defensive warfare against parasitic vegetation, ought never to prove the weakest in a contest with organisms so primitive in construction as are disease germs. But the tiniest and the simplest organism becomes a power when acting in concert with a large enough number of organisms of its own kind. There is a law in Nature that the smaller and more primitive an organism, the more rapid its reproduction, and in pursuance of this law, disease germs, when they once gain entrance into proper soil, multiply so rapidly that the mechanical obstruction of their presence in itself becomes a menace. It is in this their great numbers that they become great and prove themselves the victors in the contest for survival.

Ever since man has inhabited the earth be has 